\title{
OS IMPACTOS DAS NOVAS TECNOLOGIAS NAS EMPRESAS PRESTADORAS DE SERVIÇOS
}

* José Ernesto Lima Gonçalves

Resultados inesperados e principais exemplos de resistências à introdução de inovações em empresas de serviços brasileiras.

Several unexpected outcomes and collected examples of resistance to innovations among Brazilian service companies.

PALAVRAS-CHAVE: Tecnologia, organização, impacto das inovações.

\section{KEY WORDS:}

Technology, organization, innovation of impact.
* Engenheiro de Produção pela POLI/USP, Mestre em Administração de Empresas pela FEA/USP e Consultor em Planejamento Empresarial $\Theta$ Informática.

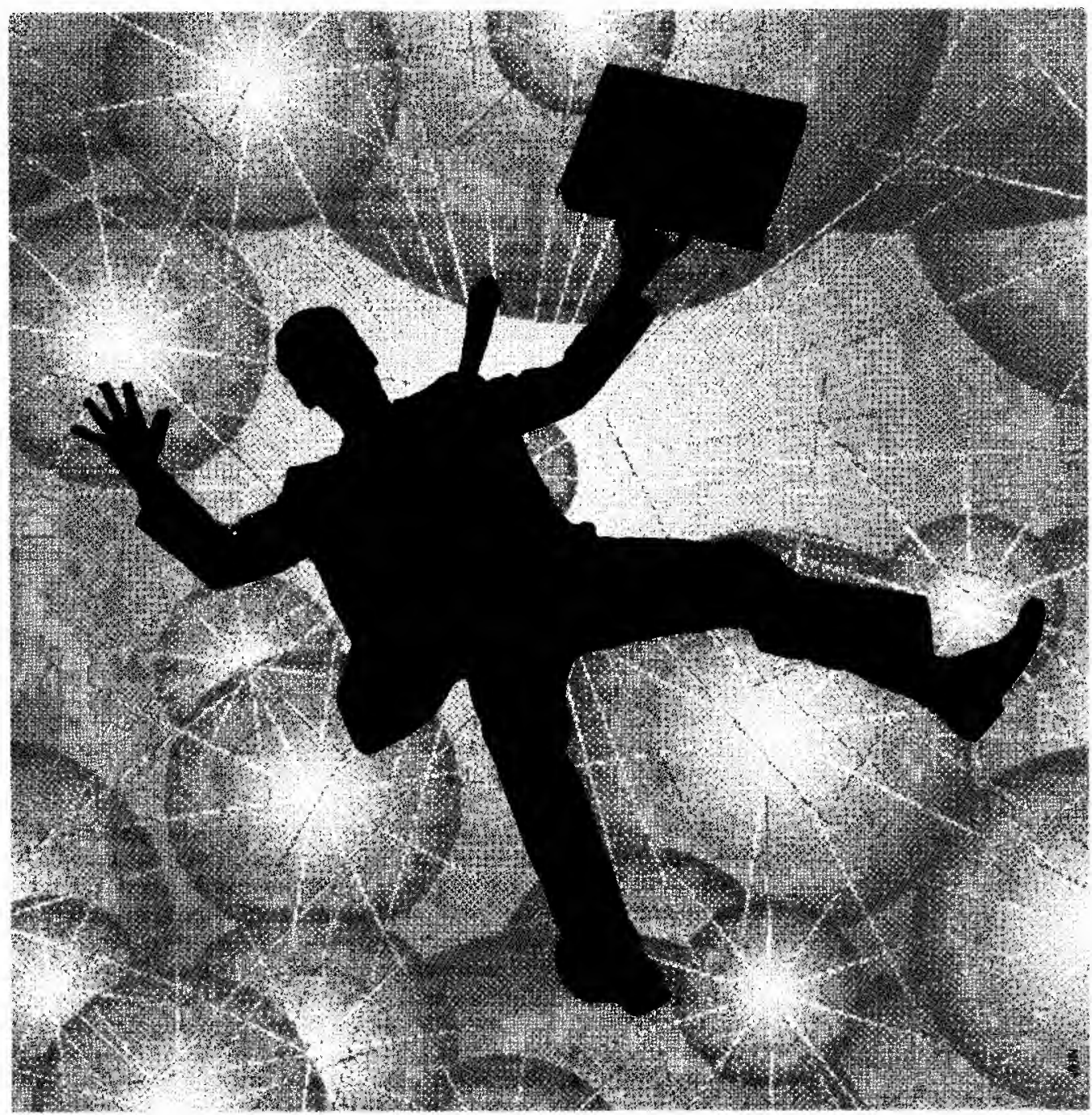


Os profissionais e professores da área de tecnologia têm necessidade de obter dados e reflexões sobre os impactos de novas tecnologias nas empresas. Em particular, este artigo tem por objetivo identificar quais são os impactos da implantação de novas tecnologias em empresas de prestação de serviços.

A implantação de novas tecnologias em empresas de prestação de serviços é um fenômeno que vem ocorrendo mais intensamente, no Brasil, desde o final da década de 70. Atualmente, é necessário incorporar ao processo de trabalho as tecnologias que possibilitem a modernização da empresa, como forma de prestar um melhor atendimento ao cliente e possibilitar um sistema de informações, controle e gerenciamento que seja capaz de gerar menores custos.

Isto ocorre devido a duas características que o mercado brasileiro vem apresentando: a intensa concorrência entre determinados tipos de empresas de serviços, onde o processo de trabalho é definidor da qualidade do atendimento; e as políticas econômicas do governo, que vêm gerando condições instáveis e precárias para as empresas nacionais em geral.

Para este artigo, tecnologia consiste em um conjunto integrado de conhecimentos, técnicas, ferramentas e procedimentos de trabalho, que pode ser manual, aplicados na produção econômica de bens e serviços. Para focalizar nossa pesquisa, restringimos nosso interesse às tecnologias que podem ser consideradas como novas. Para compreender a abrangência deste critério, é necessário esclarecer que a nova tecnologia é aquela utilizada em substituição a procedimentos anteriormente adotados na empresa. Assim, uma nova tecnologia pode ser exemplificada pela mudança de pro-

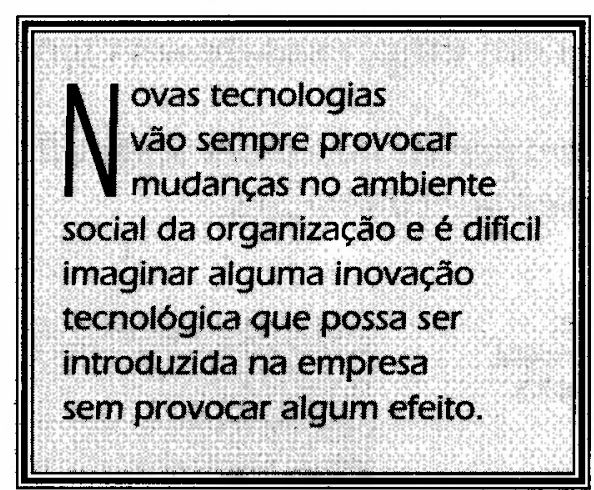
cedimentos manuais para o uso de máquinas de datilografia e de calcular, que foram substituídas por microcomputadores, e, atualmente, por redes de computadores.

A grande maioria dos trabalhos publicados no Brasil e no mundo a respeito dos impactos da tecnologia nas empresas se refere ao impacto da tecnologia sobre as empresas do setor de produção de bens. Ainda que seja razoável extrapolar algumas idéias para o setor de serviços, é importante analisar a situação para constatar até onde vão essas semelhanças. Além disto, é de se prever que os impactos de novas tecnologias sobre as empresas de serviços tenham características específicas. A bibliografia é essencialmente estrangeira, mas já temos casos e experiências nacionais, principalmente na área dos bancos, supermercados, hospitais, laboratórios de análises clínicas, escolas e editoração gráfica.

A pesquisa realizada para a preparação deste artigo traz embutidos dois objetivos específicos:

- a identificação de quais são os impactos percebidos pela organização, uma vez decidida a implantação de novas tecnologias;

- a determinação de como ocorre a reação da empresa a estes impactos, a nível de: preparação prévia, realização de ajustes no processo de implantação e sua capacidade avaliar o resultado da alteração gerada pela utilização da nova tecnologia.

Um levantamento inicial procurou definir os principais tipos de impactos das novas tecnologias, de acordo com autores nacionais e estrangeiros. Com isto, criou-se não apenas um quadro de referência para o levantamento de campo, como também um conjunto de expectativas com relação às respostas que seriam obtidas na pesquisa de campo.

Este artigo se restringe às empresas de serviços e a coleta de dados, focalizando-se nas atividades que a legislação brasileira e os hábitos do país classificam como sendo típicas de empresas particulares. Assim, incluímos empresas de serviços de engenharia, administradoras de bens e imóveis, corretoras de seguros, bancos, escritórios profissionais, entre outras. Por outro lado, não foram incluídos serviços que, no Brasil, são tipi- 
camente públicos: utilidades (fornecimento de energia elétrica, água, gás e esgotos), telefonia e correios, entre outros.

Para as entrevistas da pesquisa de campo foram selecionadas treze empresas situadas na cidade de São Paulo, representando atividades variadas do setor de serviços. Das empresas incluídas na pesquisa, quatro delas são grandes, oito são médias e uma é pequena dentro de seu respectivo segmento de atuação. Geralmente trabalham para o setor privado, mas algumas têm realizado serviços também para o setor público. Com relação ao tipo de serviços que prestam, foram incluídas empresas de consultoria, auditoria, locação, engenharia, administração de imóveis e de estacionamentos, corretagem de seguros, escola, advocacia e serviços bancários. Procuramos, com isso, apresentar um corte do elenco de ramos que compõem o setor de serviços.

Uma vez que estamos interessados na percepção da empresa como um todo a respeito dos impactos da tecnologia, as entrevistas foram realizadas com representante de nível gerencial ou de diretoria das empresas selecionadas. Os principais pontos tratados foram: a identificação da tecnologia relevante para a empresa, dos principais impactos percebidos, dos resultados esperados e obtidos, além da qualificação da empresa em termos de serviço prestado, clientes, tamanho e área de atuação. As entrevistas utilizaram perguntas abertas de acordo com um roteiro temático básico e os entrevistados foram encorajados a dar opinião abrangente sobre a empresa.

E de importância fundamental considerar que a intenção não era realizar um levantamento quantitativo, com análise de significância estatística: os dados apresentados são apenas observações qualitativas que procuram expressar as percepções dos representantes das empresas com relação à tecnologia. Desta forma, procuramos colecionar exemplos referentes a empresas brasileiras para ilustrar os pontos conceituais relevantes.

Ao final são apresentados dois casos específicos sobre o impacto da tecnologia nas empresas prestadoras de serviço: o caso da Locaset e o caso da Tecnologia Bancária Brasileira, este último considerado exemplar em termos de análise internacional. Os dados foram coletados em pesquisa de campo específica junto a prestadores de serviços e estabelecimentos bancários.

\section{A TECNOLOGIA E A INOVAÇÃo}

A tecnologia faz parte do dia-a-dia das empresas. Elas se acostumam logo a conhecer a tecnologia embutida em seus produtos e serviços, a tecnologia utilizada para produzi-los, a tecnologia empregada no controle do processo produtivo e a tecnologia característica da gestão do negócio. Alguns desses aspectos sempre recebem ênfase maior que os demais, seja por formação dos executivos, pela conjuntura ou por outro fator.

O primeiro desafio deste trabalho foi obter uma definição aceitável para a palavra tecnologia. Embora seja um termo muito utilizado, a maioria das pessoas não se preocupa em defini-lo, o que leva à previsível confusão de significados. Uma primeira definição para tecnologia é o conhecimento de relações causa-efeito contido (embutido) nas máquinas e equipamentos ${ }^{1}$ utilizados para realizar um serviço ou fabricar um produto.

Para muitos autores e usuários leigos da palavra, tecnologia se refere ao conjunto particular de dispositivos, máquinas e outros aparelhos empregados na empresa para a produção de seu resultado. ${ }^{2}$ Uma abordagem muito diferente enxerga a tecnologia como um pacote de informações organizadas, de diversos tipos, provenientes de várias fontes, obtidos através de diversos métodos, utilizado na produção de bens. ${ }^{3}$

A visão mais próxima da que defendemos é a de que a tecnologia é muito mais que apenas equipamentos, máquinas e computadores. A organização funciona a partir da operação de dois sistemas que dependem um do outro de maneira variada. Existe um sistema técnico, formado pelas técnicas, ferramentas e métodos utilizados para realizar cada tarefa. Existe também um sistema social, com suas necessidades, expectativas e sentimentos sobre o trabalho. Os dois sistemas são simultaneamente otimizados quando os requisitos da tecnologia e as necessidades das pessoas são atendidos conjuntamente. ${ }^{4}$

Assim, é possível distinguir entre tecnologia (conhecimento) e sistema técnico (combinação específica de máquinas e métodos empregados para obter um resultado desejado). Neste caso, a tecnologia seria representada por um conjunto de características específicas do sistema técnico. ${ }^{5}$
1. SPROULL, Lee, GOODMAN Paul. Technology and organizations: integration and opportunities, in GOODMAN, Paul et al. (Eds.) Technology and organizations, Jossey-Bass Publishers, 1990.

2. BARLEY, Stephen. The alignment of technology and structure through roles and networks, Administrative Science Quarterly, v. 35, n. 1, p 61-103, Mar. 1990.

3. FLEURY, Afonso C. C. Capacitação tecnológica e processo de trabalho: comparação entre o modelo japonês e o brasileiro, RAE - Revista de Administração de Empresas, v. 30 , ก. 4 p. 2330, out./dez. 1990

4. CUNNINGHAM, J. Barton, FARQUHARSON, John, HULL, Denis. A profile of human fear of technological change. Technological Forecasting and Social Change, v. 40 , p. 355-70, 1991.

5. WEICK, Karl. Technology as equivoque: sensemaking in New Technologies. In: GOODMAN, Paul. Technology and Organizations. San Francisco, JosseyBass Publishers, 1991. 
6. HUNT, Raymond. Technology and organizations. Academy of Management Journal, v. 13, n. 3, p. 235-52, Sep. 1970.

7. GONCALVES, José Ernesto L. A., GOMES, Cecília A. A tecnologia e a realizaç̃o do trabalho. RAE - Revista de Administracão de Empresas, v. 33, n. 1, jan/mar, 1993.

\section{WEICK, Karl. Op. cit.}

9. BROWNE, Lynn E. Visões conflitantes do progresso tecnológico, Economic Impact, Rio de Janeiro, v. 49, p. 8-14, jan. 1985.

10. ROSOW, J.M. People vs. hogh tech: adapting new technologies to the workplace. Management Review, New York, v. 73 , n. 9, p. 25-8+, Sep. 1984.

11. CUNNINGHAM, J. Barton, FARQUHARSON, John, HULL, Denis. Op. cit.

12. GOODMAN, Paul et al (Eds.). Technology and organizations, San Francisco, JosseyBass Publishers, 1990

13. Idem, ibidem.

14. HENDERSON, Rebecca et al. Architectural innovation: the configuration of existing product technologies and the failure of established firms. Administrative Science Quarterly, v. 35, p. 9-30, Mar. 1990

15. FLEURY, Afonso C. C. Op. cit.

16. WEICK, KARL. Op. cit.
Por fim, é interessante subdividir as tecnologias em tecnologias sociais (ligadas aos modos de organização) e tecnologias materiais (relacionadas aos processos de conversão e modos de produção). ${ }^{6}$ No primeiro caso, temos como exemplo as técnicas gerenciais, os modelos de organização, o desenvolvimento gerencial e os estudos de motivação. No segundo, os equipamentos e ferramentas utilizados na realização do trabalho.

Para que seja possível compreender os impactos da tecnologia nas organizações, é necessário também discutir o que é nova tecnologia. Diversos autores se preocupam com a definição do que vem a ser inovação tecnológica. Uma pesquisa por nós realizada para a RAE - Revista de Administração de Empresas identificou inúmeros pontos de vista a respeito. ${ }^{7}$ A nova tecnologia não é necessariamente é a que se baseia em computadores, nem é aquela completamente inédita, mas sempre é a tecnologia nova para a empresa em questão, mesmo que ela não seja nova para o mercado. ${ }^{8}$

Para Browne, "as mudanças nos processos de produção e nos modelos dos produtos que sejam a base do progresso tecnológico constituem inovações. Uma distinção importante é aquela entre invenção e inovação. A invenção é a descoberta das relações científicas ou técnicas que tornam possível o novo modo de fazer coisas; a inovação é sua aplicação comercial."

Uma linha de abordagem comum deste conceito entende que a maior parte das inovações se relaciona com a descoberta de um modo melhor e/ou mais eficiente e menos dependente de mão-de-obra para executar uma função já existente. ${ }^{10}$ Restringir o interesse pela inovação tecnológica à eficiência do processo é, no entanto, desvalorizar a tecnologia.

\section{OS EFEITOS DAS NOVAS TECNOLOGIAS}

Novas tecnologias vão sempre provocar mudanças no ambiente social da organização e é difícil imaginar alguma inovação tecnológica que pudesse ser introduzida na empresa sem provocar algum efeito. ${ }^{11}$ Pode-se mesmo afirmar que se uma inovação não trouxer nenhum resultado, teria sido melhor não investir nela, já que ela não se pagou.

Considerando a amplitude dos conceitos de novas tecnologias e inovações tecnológicas usualmente adotados, é possível imaginar a enorme abrangência de seus efeitos, tanto do ponto de vista social quanto econômico, político e psicológico na realização do trabalho.

Além de presente em todas as formas de organização, ${ }^{12}$ a tecnologia é também uma potente força. Ela pode estender as capacitações humanas. A revolução industrial utilizou tecnologia para estender a capacidade física do homem realizar trabalho. A revolução da informática está estendendo a nossa capacidade de realizar trabalho mental e redistribuindo o tempo que dedicamos à realização das nossas diversas atividades.

Como observa Goodman,,$^{13}$ a tecnologia é dinâmica e evolui rapidamente. O seu desenvolvimento está longe de terminar e, no ritmo atual, deve durar pelo próximo século. O rápido desenvolvimento das novas formas de tecnologia dificulta identificar como as novas formas de organização parecerão no futuro.

Existem vários tipos de inovação, com diferentes tipos de efeitos competitivos e o assunto tem sido um tema importante na literatura que trata do assunto desde Schumpeter, em 1942. Os diversos impactos da tecnologia sobre as competências características da empresa podem ser classificadas em duas dimensões: ${ }^{14}$ a dos conceitos nucleares da empresa e a da ligação entre esses conceitos e os componentes dos serviços prestados.

Seguindo esta linha de raciocínio, as inovações tecnológicas podem ser radicais, importantes ou incrementais. As inovações radicais têm amplo impacto sobre o sistema produtivo, podendo tornar obsoleta, total ou parcialmente, a base técnica existente. Geralmente são intensivas em ciência e um bom exemplo é o surgimento da microeletrônica. As inovações importantes são aquelas que têm impacto sobre certos mercados, podendo modificar a dinâmica da competição. Geralmente correspondem ao lançamento de novos produtos e processos. Como exemplo, podemos mencionar a introdução do nylon. As inovações incrementais correspondem aos resultados dos esforços cotidianos para aperfeiçoar os produtos e os processos existentes. ${ }^{15}$

Ainda sob o aspecto da gestão das empresas, observamos que a tecnologia e a inovação tecnológica são claramente vistas como fonte de incertezas para as empresas, ${ }^{16}$ não apenas por causa dos desafios que trazem ao alterar as ca- 
racterísticas internas das empresas, mas também por causa dos impactos nas condições de competição, investimentos e rentabilidade das empresas.

A introdução de inovações tecnológicas já foi equiparada a um "choque exógeno", que atuaria sobre as empresas, provavelmente provocando reestruturações abrangentes nela. ${ }^{17} \mathrm{~A}$ introdução de inovações tecnológicas também pode ser encarada como o momento de se promover na empresa as mudanças importantes e desejadas, mas que esperavam o "pretexto". ${ }^{18}$

A tecnologia é instrumental na industrialização dos serviços,,$^{19}$ mecanismo pelo qual o serviço é prestado de forma a abranger maior público, com maior eficiência e menores custos. O telemarketing, o supermercado e os seguros em grupo são exemplos de serviços industrializados e eles não seriam viáveis sem a tecnologia que empregam.

\section{O PAPEL DA INFORMÁTICA}

Dentre as várias tecnologias que tiveram impacto na realização do trabalho recentemente, a de informática é a que tem despertado maior atenção. Sua utilização é muito disseminada em diversos ambientes de trabalho e a abrangência de seus impactos é muito ampla, justificando o interesse em analisá-los mais atentamente. Um exemplo destes impactos é a intensificação da preocupação com as informações, que, ao serem mais facilmente utilizadas com a informática, geram uma série de alterações na organização das empresas, inclusive a nivel da relação entre as suas diversas áreas e as pessoas que nela atuam.

Mais recentemente, a informática uniu-se às telecomunicações e à automação de escritórios para dar lugar à TI (tecnologia de informação). Amplificado por esta relação fortemente sinergética, o potencial de impacto da informática fez-se sentir nos mais diferentes setores da atuação.

$\mathrm{Na}$ opinião de Zuboff, que é autora de uma das principais obras sobre o papel da tecnologia de informação no local de trabalho moderno, as pessoas passam maior parte do tempo discutindo os dados disponíveis. Por um lado, informação é algo muito abstrato e quanto mais abstrato e mais presente no dia-a-dia, mais importante é partilhar opiniões e interpretações com outras pessoas. ${ }^{20}$ Por outro lado, é necessário dispor de tempo para discutir os assuntos relevantes e a tecnologia provavelmente consegue liberar tempo das pessoas para essa discussão. A mesma tecnologia também auxilia na avaliação dos assuntos através de suas técnicas de análise.

A utilização da informática não se restringe ao escritório e seu impacto também é percebido na fábrica e no comércio. Muitos têm falado da "fábrica do futuro", com a criação de cenários muito diferentes dependendo da linha dos autores. ${ }^{21}$ Por outro lado, técnicas desenvolvidas no ambiente de produção para análise da forma de realização do trabalho têm sido aplicadas nos escritórios, como é o caso da abordagem de sistemas sócio-técnicos. ${ }^{22}$

Tendo penetrado nas mais diversas organizações e na vida pessoal de parte considerável da população mundial, a tecnologia de informação evolui rapidamente, de forma a atingir cada vez mais um padrão de preço, qualidade e aspecto físico adequado ao seu reconhecimento como um produto de demanda básica por parte dos indivíduos e das organizações.

O aparecimento do computador foi um elemento disparador de um processo de exacerbação das diferenças entre as formas tradicionais de realizar o trabalho e as novas formas. Esta tecnologia é tão importante que por si só justificaria esta pesquisa para que fossem explorados os mais diversos aspectos relativos aos impactos que podem ser percebidos na preparação da introdução da tecnologia de informação em uma organização, no decorrer deste processo, durante a absorção desta tecnologia, e nas características da organização após tudo isto.

\section{A ABRANGÊNCIA DO CONCEITO DE SERVIÇO}

O segundo conceito fundamental nesta pesquisa é o de serviço. Embora não haja um consenso definitivo sobre a definição de serviço, considera-se que o setor de serviços inclui todas as atividades econômicas cujo resultado 1. não é um produto físico; 2 . é geralmente consumido na época da produção e 3. apresenta valor adicionado em formas que são essencialmente intangíveis para o consumidor. ${ }^{23}$ São exemplos radicalmente diferentes de
17. BURKHARDT, Marlene, BRASS, DANIEL. Changing patterns or patterns of change: the effects of a change in technology on social network structure and power. Adminis-trative Science Quarterly, v. 35, p. 104$27,1990$.

18. GONÇALVES, José Ernesto Lima. A informatização de pequenas e médias empresas, notas de aula, FDTE-Poli, Universidade de São Paulo, 1984.

19. LEVITT, Theodore. The industrialization of service. Harvard Busines Review, p.6374, Sep./Out. 1976.

20. FRITZ, N.R. Information technology and the changing workplace: an interview with Shoshana Zuboff, Personnel, Saranac Lake, v. 66, n. 6, p. 26 , June 1989.

21. LIKER, J.K. et al. Changing everything all at once: work life and technological change, Sloan Management Review, Cambridge, v. 28 , n. 4 , p. 29 47. Summer 1987

22. CUNNINGHAM, J. Barton, et al. Op. cit; CALVIN, Pava. Managing new office it technology. New York: The Free Press, 1983.

23. QUINN, James Brian. Inte/ligent enterprise. New York: The Free Press, 1992. 
serviços, mas igualmente aceitáveis dentro desta definição: o transporte de mercadorias de todos os tipos, os reparos executados pelo encanador, a venda de alimentos pelo supermercado e o fornecimento de energia elétrica.

A justificativa para a opção de avaliar o setor de serviços baseia-se no fato de que este setor vem cada vez mais exercendo um papel importante na economia brasileira, e a tendência é de seu crescimento. Aliás, esta é uma tendência generalizada nas economias modernas e desenvolvidas, de acordo com a imprensa internacional especializada. Assim, compreender o que se passa no interior destas empresas, principalmente no que se refere às inovações em seus procedimentos de trabalho, é necessário para gerar condições de formação de uma mentalidade gerencial melhor preparada para o setor.

Ainda há muito pouca discussão sobre este setor nos trabalhos destinados à compreensão da inovação tecnológica. Muitos estudos já se preocuparam com os impactos da automação industrial, mas há poucas análises científicas dos impactos dessas inovações sobre as empresas de prestação de serviços.

O setor de serviços tem importância crescente. Suas empresas não podem ser consideradas pequenas, nem seus negócios são sempre de pequena escala. Se há algumas décadas a grande maioria das empresas da Forbes 500 eram puramente industriais (General Motors, Ford, Texaco, General Electric etc.), hoje temos bancos, empresas de informática, empresas de telecomunicações, transportadoras e redes de lojas (Sears, Roebuck, BankAmerica, AT\&T, Wal-Mart, ITT, American Express etc.) ${ }^{24}$ dominando aquela lista. No Brasil, a edição de 1992 das Maiores e Melhores de Exame mostra que 14 das 50 maiores empresas do país eram prestadoras de serviços (entre as quais citamos Varig, Carrefour, Pão de Açucar, Shell, Lojas Americanas e Mesbla). E se nove entre dez maiores fortunas do mundo de 50 anos atrás pertenciam a industriais e fazendeiros, hoje muitas pertencem a pessoas que controlam o mundo das informações, do entretenimento e do comércio.

As empresas do setor de serviços têm investido mais em recursos produtivos que o setor de produção de bens. Empregam $77 \%$ da mão-de-obra produtiva americana e produzem $74 \%$ do valor adicionado na economia dos Estados Unidos. Em outros países industrializados o desempenho do setor de serviços tem sido semelhante. ${ }^{25}$

No Brasil, o setor também tem crescido e os casos de sucesso observados são equivalentes a muitos existentes em outros países. As nossas empresas de telecomunicações e transportes precisaram se desenvolver muito nas últimas décadas para cobrir nossas distâncias internas. Os eternos desafios de nossa economia levaram ao desenvolvimento de um poderoso setor de serviços financeiros, que vão dos bancos, pelas seguradoras até as corretoras de valores. O tamanho de nossa população levou à estruturação de uma grande rede escolar e à montagem de uma enorme rede de transporte e distribuição de alimentos para o atendimento das nossas necessidades de alimentação. Grandes centros consumidores viabilizaram o surgimento de cadeias de supermercados, hospitais bem equipados e abrangentes redes de estabelecimentos de ensino públicos e particulares.

\section{OS TRÊS NIVEIS DA RELAÇÃO ENTRE TECNOLOGIA E EMPRESA}

Partimos da premissa de que o relacionamento entre tecnologia e empresa ocorre em três níveis: o das pessoas (indivíduos), o dos grupos de indivíduos e o da empresa como um todo. Esta forma analítica nos parece adequada tanto para avaliar os diversos tipos de impactos da tecnologia quanto à sua origem, como também para entender a abrangência da relação entre tecnologia e empresa. ${ }^{26}$

Cada um desses níveis de relacionamento, por sua vez, abrange diversos impactos da tecnologia sobre a empresa e seus componentes. $O$ quadro 1 indica os impactos da tecnologia que interessam neste nosso estudo. Nosso

24. Forbes 500,27 de abril de 1992, p.192.

25. QUINN, James Brian. Op. cit.

26. GONÇALVES, José Ernesto et al. A tecnologia $e$ a realização do trabalho. Op. cit. objeto de estudo se situa claramente ao nível micro, interno das organizações, com foco especificamente colocado na empresa.

No menor nível de análise possível, o da realização do trabalho, os principais impactos da tecnologia sobre a realização do trabalho podem ser organizados em seis grupos:

- conteúdo e natureza das tarefas a serem executadas;

- habilidades (skills) exigidos dos operadores;

- pressões e ritmo de trabalho;

- interação entre as pessoas que realizam o trabalho; 


\begin{tabular}{|c|c|c|}
\hline \multicolumn{3}{|c|}{ Quadro 1} \\
\hline Nivel & Foco & Impacto \\
\hline micro & indivíduo & $\begin{array}{l}\text { temores } \\
\text { resistências } \\
\text { ajustamento } \\
\text { formação / enquadramento } \\
\text { desempenho } \\
\text { saüde ocupacional }\end{array}$ \\
\hline & grupo & $\begin{array}{ll}\text { processos grupais } & \text { liderança } \\
\text { nível relação }\end{array}$ \\
\hline & empresá & $\begin{array}{l}\text { organização e estrutura } \\
\text { imagem } \\
\text { competitividade } \\
\text { administração } \\
\text { desempenho } \\
\text { qualidade e adequação do produto } \\
\text { investimentos } \\
\text { pessoal (qualificação e número) * * } \\
\text { aspectos psicológicos }\end{array}$ \\
\hline macro & economia & $\begin{array}{l}\text { produtividade } \\
\text { produção de bens e serviços }\end{array}$ \\
\hline & mercado de consuma & produtos disponíveis \\
\hline & mercado de trabalho & $\begin{array}{l}\text { nivel de emprego } \\
\text { nivel de remuneração }\end{array}$ \\
\hline & ambiente & $\begin{array}{l}\text { contaminação } \\
\text { ruído } \\
\text { exploraçãa de recursos }\end{array}$ \\
\hline & 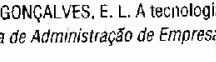 & $\begin{array}{l}\text { açáo da trabalho. } \\
\text { 1. p. p.106 } 21 .\end{array}$ \\
\hline
\end{tabular}

- localização e distribuição das pessoas que realizam o trabalho;

* horário e duração das jornadas de trabalho.

Esses grupos, isolados ou em conjunto, têm o potencial de interferir em um ou mais dos aspectos-chave das empresas: estrutura organizacional, estrutura do processo produtivo, composição do quadro de pessoal, parâmetros de desempenho e gerenciabilidade. Essa interferência pode ser mais ou menos profunda, em função da intensidade do impacto da tecnologia sobre a realização do trabalho. Sob este ponto de vista, o impacto da tecnologia tem efeito ascendente, a partir dos elementos de menor ordem na escala organizacional.

A relação mais abrangente entre tecnologia e empresa e, portanto, a mais forte relação "causa-efeito" entre clas é a de natureza estratégica. A competência tecnológica influencia as estratégias da organização e, portanto, tem influência direta nos sistemas e na estrutura operacionais. Assim, tem impacto direto no contexto, configuração, arranjo e natureza das atividades produtivas. ${ }^{27}$

A revista Training, por exemplo, comenta como a automação de escritórios está modificando o job mix nas empresas. ${ }^{28}$ Já outros autores apontam a alteração no perfil da mão-de-obra empregada. 29

As mudanças tecnológicas desestruturam o trabalho ao nível micro, já que alteram a natureza dos elementos constitutivos das tarefas. Alguns desses elementos são eliminados ou absorvidos pela tecnologia enquanto outros são diminuídos ou mesmo ampliados. Já que esses elementos são alterados, a tarefa como um todo também deve se alterar.

Numa dimensão mais ampla, a techologia provoca alterações no sistema operacional das cmpresas, ${ }^{31}$ na forma como as empresas funcionam.
27. WILD, Ray, Technology work and workplaces. Management Decision, v. 29, п. 8 1991.

28. Survey sinks miths about office automation revolution. Training and Development Journal, July 1985.

29. RODRIGUES, Suzana Braga A informática na organização e no trabalho. RAE - Revista de Administração de Empresas, Sāo Paulo, v, 28, n. 3, p. 43-50, jul/set. 1988.

30. WILD, Ray. Op. cit.

31. MCFARLAN, F. Warren. Information Technology changes the way you compete. Harvard Business Review, p.98-103, May.IJun. 1984. 
A utilização de sistemas de automaçã̃o de escritórios, por exemplo, provoca alterações nos procedimentos de trabalho, na programação das atividades, na descrição das funçöes e no ambiente de trabalho. Imagine-se, por exemplo, a importância de um sistema de correio eletrônico que permita dispensar os bilhetes e as requisiçóes de serviços, a espera pelo porlaAor do correio interno e os controles de protocolos. Com a sua utilização, estariam sendo alterados, de uma vez, diversos aspectos do trabalho interno da organização.

As principais inovaçõos tecnológicas observadas nas entrevistas estão reunidas no quadro 2. Em diversos casos, a inovação se refere ao início de utilizaçăo de diferentes ferramentas de informática nas empresas, mas também temos casos de um novo método de alfabeticação, a obtenção de knowhow em uma nova área e combinação de várias tecnologias.

Quadro 2

Inovaçōes tecnológicas e seus objetivos

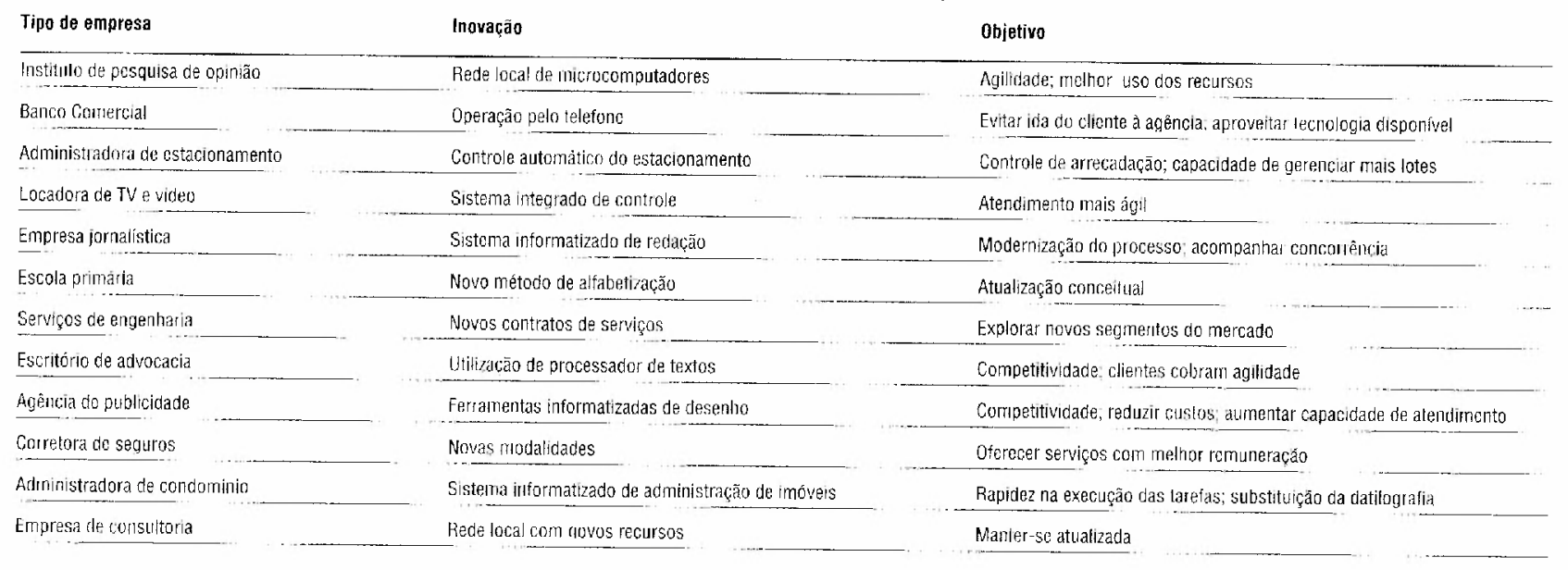

Os objetivos perseguidos pelas empresas ao adotarem innvaçôes tecnológicas variam bastante, mas geralmente săo de natureza aquisitiva. Existe uma forte preocupação com a competitividade da empresa c o seu desempenho perante a concorrência. As pressões dos clientes também estão presentes, mas muitas empresas têm objetivos internos importantes, como a atualização, a redução de custos, o aproveitamento de recursos e a gestão da empresa.

No início desta pesquisa, pensamos que as empresas entrevistadas assumiriam uma de duas posições quando perguntadas sobre tecnologia: não saber o que vem a ser tecnologia ou responder sobre informática. No entanto, não foi isso que se observou: todos os entrevistados falaram sobre a tecnologia e manifestaram preocupação com ela, mesmo que com abordagem simplista e superficial. Ao longo da pesquisa surgiram algumas respostas surpreendentes e algumas posições sobre informática, especialmente nas empresas em que cla realmente têm sido muito relevante.

Algumas empresas deram sua visão de tecnologia, independente de TI. A filial brasileira do Instituto Gallup realiza pesquisas de opinião para seus clientes com um quadro fixo de 70 pessoas, complementado por mais de 300 pesquisadores temporários. Os clientes típicos do instituto são os órgãos de imprensa, as grandes empresas industriais e comerciais, embora também sejam atendidos políticos e candidatos a cargos eletivos. O Gallup lida com tecnologia em dois níveis: por um lado, a pesquisa de opinião é uma tecnologia empregada pelos clientes do instituto para seu planejamento e decisão. Essa tecnologia tem sido desenvolvida e aperfeiçoada pioneiramente pelo Gallup americano e as novidades são posteriormente transmitidas aos institutos associados no mundo todo. Por outro, a tecnologia, 
na forma da informática, veio viabilizar a rapidez e baixar custos de realização de análises sofisticadas.

Em sucessivas ondas de renovação, o Gallup brasileiro passou dos processos essencialmente manuais para o processamento de cartões perfurados, depois para a utilização de computadores grandes das universidades até adquirir seus primeiros computadores próprios. Desde meados de 1992, está passando a operar sua própria rede de microcomputadores, que interliga as diversas áreas da empresa. O pessoal está passando por um processo para se acostumar a trabalhar com dados que estão simultaneamente disponíveis para todas as pessoas dentro do instituto. Não existe mais, também, a centralização das atividades de processamento no CPD: agora todos estão envolvidos no processamento dos dados e cada um faz a sua parte.

A inovação tecnológica aparece também nas escolas. No caso da Lourenço Castanho, uma escola de primeiro grau com 1.500 alunos de São Paulo, a inovação surgiu em 1989 na forma de um novo método de alfabetização, em decorrência do aparecimento de novas teorias e estudos a respeito do assunto. Foi necessário preparar os professores para a aplicação do novo método e convencê-los a aceitar uma carga maior de trabalho, pelo menos durante a etapa inicial do processo. Tanto o processo de preparação dos professores e de introdução do novo método, como o surgimento dos resultados foram demorados, o que provavelmente é característico desta tecnologia.

Três grupos distintos estão envolvidos na introdução da inovação tecnológica na escola e têm percepções diferentes de suas consequiências: os professores, os alunos e os pais dos alunos. No caso da escola estudada, tanto os professores como os pais se preocuparam bastante com o novo método, especialmente por causa da dificuldade de avaliar os resultados.

A Cmel Montagens Ltda. é uma empresa instalada em São Paulo que se especializa na prestação de serviços de engenharia. Tem mais de 350 empregados, que chegam a 800 nos grandes projetos e fatura 15 milhões de dólares anuais. Trabalha basicamente nas áreas de instalações industriais, reestruturação de arranjo físico industrial e manutenção de instalações petrolíferas. A empresa considera que o know-how adquirido na execução dos trabalhos contratados é a principal tecnologia de que dispõe e de que se utiliza. A inovação tecnológica está associada aos trabalhos novos, que representam a oportunidade e a necessidade de serem adquiridos novos conhecimentos. Reconhece que existem outras tecnologias importantes para a empresa, entre as quais a informática, que é empregada na modernização dos processos gerenciais.

Seguindo uma estratégia de renovação da linha de serviços oferecidos, com o objetivo de se posicionar melhor no concorrido mercado em que atua, a empresa decidiu assimilar novas tecnologias para atender a novos ramos do mercado. Em 1988, decidiu começar a prestar serviços de reorganização de arranjo físico-industrial. Nessa modalidade de serviço, a empresa é contratada para executar as alterações que são projetadas pelos especialistas em processo industrial para as fábricas que estão mudando suas linhas de equipamentos.

Depois de entrar em contato com um novo know-how, desenvolvendo um contrato referente a um novo serviço, a empresa geralmente leva 18 meses para se sentir familiarizada com ele e ter confiança para vender novamente $o$ mesmo serviço. Durante esse período a nova equipe é desenvolvida e preparada para realizar o novo tipo de projeto. Embora seja possível procurar quem já fez, não é comum encontrar os técnicos especialistas no mercado e as empresas que já têm experiência escondem seu know-how. Assim, a Cmel teve que investir na preparação de sua própria equipe. Como conseqüência, a empresa prefere manter a sua equipe nos períodos entre projetos, para preservar sua capacidade de realizar trabalhos específicos.

Outro caso de tecnologia associada ao know-how da empresa parece ser o das corretoras de seguros. As corretoras de seguros promovem a ligação entre as empresas seguradoras e os clientes interessados nos seguros. Nas corretoras, o técnico em seguros analisa a situação proposta pelo cliente e desenha a solução mais adequada para o cliente, a partir de produtos padronizados pelas seguradoras. A partir desse ponto, a empresa passa a agir como intermediária na transação comercial de venda do seguro ao cliente e vai continuar a dar-lhe apoio e atendimento durante a vigência do contrato. A tecnologia específica corresponde à capacidade de identificar os aspectos relevantes da situação do cliente para a composição do pacote de seguros a ser encomendado à seguradora. É vital, 
portanto, que a corretora disponha de pessoal com muito conhecimento do funcionamento do mercado segurador.

\section{AS INOVACOES TIVERAM ORIGEM NO TOPO}

As observações referentes à iniciativa da adoção da inovação tecnológica estão resumidas no quadro 3 . Nele podemos observar que a diretoria das empresas é a origem e o principal suporte de todas as iniciativas de inovação tecnológica entre as empresas entrevistadas. Algumas vezes a diretoria de uma das áreas funcionais propõe a inovação, provavelmente motivada por interesse local. Na maioria dos casos, no entanto, as inovações decorreram de decisões tomadas pelo principal executivo.

No caso da administradora de imóveis, a gerente resolveu aderir à utilização de programas para o gerenciamento de imóveis depois de reclamações por parte dos clientes, que achavam o serviço lento, pouco flexível e primitivo.

\begin{tabular}{|c|c|c|}
\hline \multicolumn{3}{|c|}{ Quadro 3} \\
\hline \multicolumn{3}{|c|}{ Origem e resistências às inovações } \\
\hline Tipo de empresa & Origem da inovação & Resistências \\
\hline Instituto de pesquisa de opinião & Diretoria & Oposiçāo do grupo do CPD; resistência a assumir serviço do CPD \\
\hline Banco Comercial & Diretoria comercial & Nenhuma identificada \\
\hline Administradora de estacionamento & Diretoria & Empregados não gostam da introdução de controles \\
\hline Locadora de TV e video & Diretoria & Questionaram a mudança, pois já usavam informática \\
\hline Empresa jornalistica & Área industrial & Pouquissima, pois a mudança era esperada e desejada \\
\hline Escola primária & Diretoria & Alunos resistiram ao novo método; professores acharam carga excessiva \\
\hline Serviços de engenharia & Diretoria comercial (oportunidade) & Nenhuma percebida \\
\hline Escritório de advocacia & Diretoria (sócio viu em concorrente) & Nenhuma percebida \\
\hline Agência de publicidade & Diretoria (śćcio viu em concorrente) & Oposição dos empregados antigos; integração entre áreas não era aceita \\
\hline Corretora de seguros & Área comercial & Nenhuma percebida \\
\hline Administradora de condominio & Diretoria & Medo inicial \\
\hline Empresa de consultoria & Diretoria (sócios) & Nenhuma percebida \\
\hline
\end{tabular}

Na empresa O Estado de S. Paulo, a inovação foi praticamente imposta pela diretoria de produção, que procurava meios de modernizar o processo de produção dos jornais. A diretoria colegiada acompanhava os movimentos da concorrência, que já havia adotado técnicas modernas e recursos eletrônicos de redação. Nesse quadro, a proposta da diretoria de produção veio ao encontro da expectativa dos demais diretores. Mesmo a nível dos profissionais da redação, a mudança era esperada com ansiedade e foi absorvida com facilidade.

De acordo com os dados coletados, os objetivos almejados pelas empresas com a inovação da tecnologia eram muitas vezes pequenos, restritos e limitados e, na realidade, foram superados muitas vezes. Os casos apresentados a seguir ilustram este ponto.

O programa de processamento de textos foi a primeira ferramenta de informática que a administradora de condomínio Portes utilizou, numa substituição da máquina de escrever, no final de 1990. Procurava com isto agilizar seus serviços, reduzindo o trabalho de redatilografia de textos semelhantes e abrindo caminho para utilizar um programa de mala direta. A gerente do escritório percebia que seus nove empregados realizavam muitas tarefas repetitivas e procurou simplificar o trabalho. Aos poucos se interessou por um sistema de gerenciamento de imóveis, que veio a automatizar inúmeras tarefas antes realizadas à mão. De acordo com a gerente do escritório, a falta de familiaridade com a informática no início impedia até mesmo que as possibilidades mais amplas da utilizaçăo da informática pudes- 
sem ser vislumbradas, quanto mais avaliadas. Por isto mesmo, seus objetivos iniciais não eram ambiciosos e praticamente se restringiam a facilitar a operação do escritório.

Por outro lado, algumas empresas mencionaram objetivos específicos que procuravam alcançar através de inovações tecnológicas. Certas empresas prestadoras de serviços precisam avançar na tecnologia para estar à frente dos seus clientes, seja para manter uma imagem de vanguarda, seja para poder oferecer serviços atualizados. Este é o caso específico das empresas de auditoria e consultoria, como a KPMG e a Officeware. Essas empresas incentivam seus empregados a utilizarem as novas ferramentas tecnológicas que serão posteriormente oferecidas aos seus clientes. Dessa forma, essas ferramentas podem ser melhor avaliadas e os empregados já estão familiarizados com as ferramentas selecionadas quando chega o momento de utilizá-las para os clientes.

A Officeware é uma empresa de projetos e consultoria na área de tecnologia de informação, que tem como clientes empresas de médio e grande portes que atuam no país. Sua equipe básica é de 15 consultores e fatura mais de 700.000 dólares anuais. No caso da Officeware, seus consultores devem conhecer profundamente os produtos de informática que recomendarão aos seus clientes. Para ela, os novos produtos e os recursos que eles colocam à disposição dos seus usuários constituem as inovações tecnológicas relevantes. Em particular, a partir de 1992, passou a trabalhar com micros ligados em rede local no próprio escritório, de forma a preparar melhor seus consultores nas condições de trabalho de seus clientes. A empresa considera fundamental estar sempre procurando conhecer as novidades tecnológicas importantes para seus clientes.

A KPMG é uma das maiores e mais tradicionais empresas de auditoria do mundo. Seu escritório em São Paulo reúne 600 dos 900 empregados que a empresa tem no país. Entre seus clientes típicos estão as empresas industriais, as seguradoras e as empresas financeiras de grande porte. No caso da KPMG, as novas sistemáticas de trabalho, novas técnicas de apuração do resultado e do desempenho das empresas e novos processos de análise de empresas constituem as inovações tecnológicas significativas. Os motivos básicos para pesquisa de inovações são diminuir os custos e oferecer resultados mais rápidos e mais confiáveis aos clientes.

Estas duas empresas têm outra característica, muito interessante, inerente à sua atividade: elas estão permanentemente procurando as inovações tecnológicas e se submetendo a elas em primeiro lugar. $O$ movimento de mudança é contínuo e o estado de alerta para as inovações é permanente.

A administração de lotes de estacionamento ilustra o caso em que a tecnologia foi utilizada como meio de melhorar o controle em uma atividade em que evasão de receitas era um problema crônico. Os controles de utilização das vagas nos estacionamentos e da receita auferida sempre constituem o calcanhar de Aquiles da administração desse negócio. É muito comum que empregados inescrupulosos utilizem de artimanhas para desviar parte da féria diária. Algumas vezes, o esquema de evasão envolve os próprios clientes dos estacionamentos, interessados em estacionar sem pagar o devido. $O$ problema é tão freqüente que algumas operadoras de estacionamentos chegam a considerar normal a perda de uma certa porcentagem da receita por causa da evasão.

No início de 1992, a Área Parking, administradora de estacionamentos de São Paulo, com 140 empregados e faturamento de 1,5 milhões de dólares em 1992, resolveu automatizar a operação dos seus lotes com o objetivo de melhorar o nivel do controle sobre a operação deles. Foi buscar a tecnologia mais utilizada no mundo para essa finalidade. Instalou aparelhos que emitem bilhete de estacionamento na entrada do veículo e só abrem a cancela para o veículo sair quando o bilhete devidamente pago é apresentado ao equipamento na saída. No início, houve resistência por parte de alguns empregados e clientes, identificados posteriormente como envolvidos nos esquemas de evasão. De acordo com a empresa, os clientes perceberam o aperfeiçoamento do serviço, em termos de rapidez de atendimento. Logo a seguir, a empresa notou os resultados e a evasão estimada caiu a niveis desprezíveis.

A automatização dos controles permitiu que a empresa passasse a operar maior número de lotes de estacionamento com o mesmo efetivo de controle no escritório: passou de 20 para quase 30 estacionamentos em menos de um ano. 


\section{Quadro 4}

\section{Percepção da preparação e do impacto}

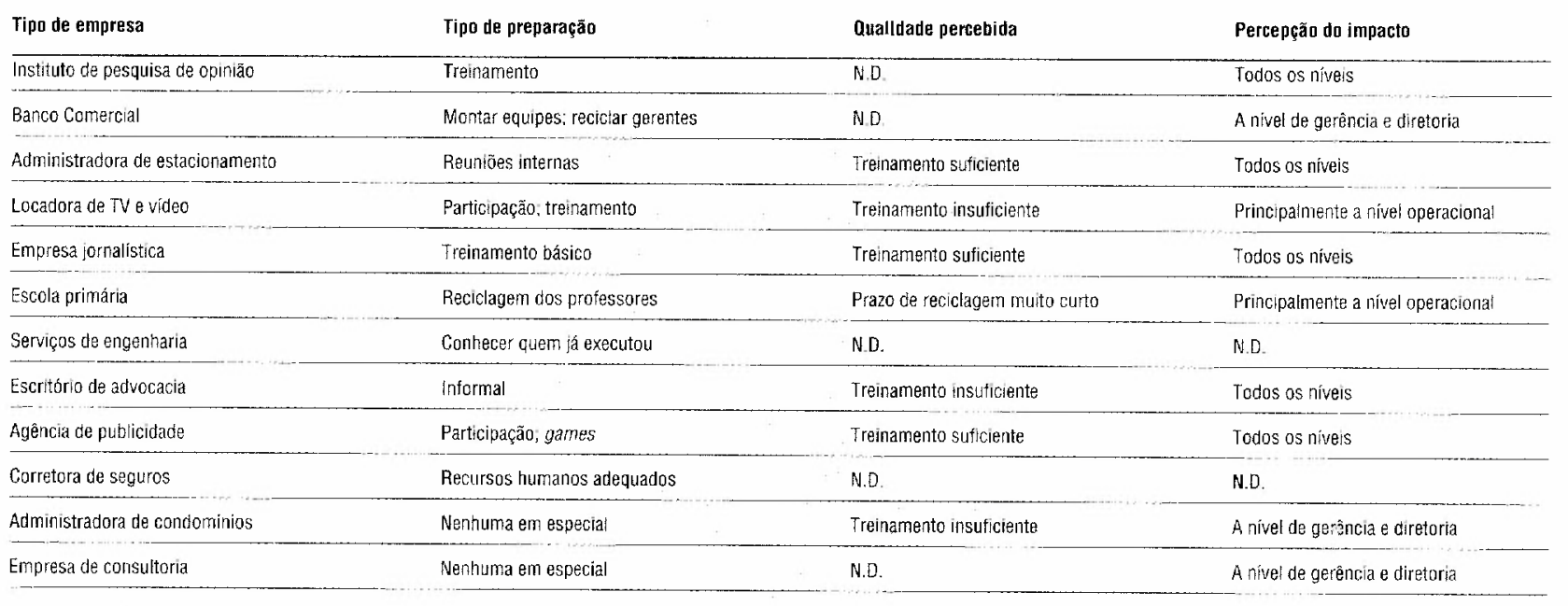

N.D. = Năo disponivel

As grandes empresas também procuram as inovações tecnológicas como suporte à implementação de suas estratégias. O banco ltaú é uma das maiores e mais completas instituições bancárias brasileiras. Tem $41.500 \mathrm{em}-$ pregados e receita acima de 19 bilhões de dólares em 1992. Recentemente decidiu-se pela utilização de novos recursos da tecnologia de processamento de dados, das telecomunicações e das técnicas de gerenciamento da informação para reprojetar o acesso do cliente ao banco. O gerente e os funcionários da agência precisam ter tempo livre para fazer as tarefas que são o núcleo da atividade bancária: negociar, vender dinheiro c captar novos clientes. As demais tarefas que os bancos desempenham são não produtivas e, na medida do possivel, devem ser feitas de forma a não consumir muitos recursos do banco. Desta maneira, se é possivel resolver o assunto do cliente pelo telefone, pelo fax ou pelo terminal remoto, é preferivel para liberar o pessoal da agência. O Banco Itaú desenvolveu um pacote de soluçôes deste tipo, a partir de 1990. Além disto, está instalando em suas agências um número muito maior de equipamentos de auto-serviço (cash dispensers, ATM, terminais de consultas e extratos) do que já teve. Novamente, a intenção é que o cliente realize as operações mais simples por conta própria, liberando o pessoal da agência para as atividades mais complicadas e interessantes para o banco.

$\mathrm{O}$ aperfeiçoamento dos processos administrativos é uma das aplicações mais interessantes de novas tecnologias por causa dos ganhos possíveis. Nos últimos quatro anos a l.ocaset, que é uma empresa especializada no aluguel de aparelhos de televisão e vídeo para hotéis, eventos c clientes particulares, passou a utilizar controles informatizados no gerenciamento dos seus contratos. No inicio, um microcomputador era utilizado no controle de aparelhos locados e de parcelas pendentes de cobrança. Há dois anos, foi adotado um sistema integrado de gerenciamento que acompanha cada contrato do início até o final de sua existência. Este sistema integra as diversas estações por que passam os contratos, eliminando o fluxo de papel que caracterizava a operação da empresa. Na Locaset, o próprio contrato é um documento que só existe fisicamente para conter as assinaturas dos envolvidos, por exigência legal. O caso da Locaset é apresentado em detalhes ao final do artigo.

Uma das medidas a que as cmpresas tradicionalmente recorrem para facilitar a absorção de inovações tecnológicas pelo seu pessoal é o treinamento dos empregados. De acordo com a nossa pesquisa, praticamente todas as empresas utilizaram alguma forma de treinamento, não apenas para capacitar seus empregados, como também numa etapa preliminar de familiarização com a novidade. Uma das empresas utilizou "joguinhos" para conseguir a aproximação de empregados refratários à utilização de computadores. Al- 
gumas empresas promoveram ciclos de treinamento formal, enquanto outras adotaram esquemas informais. O quadro 4 resume as observações neste sentido.

A percepção do pessoal que passou a utilizar a nova tecnologia com relação ao preparo a que foram submetidos também foi pesquisada. Percebe-se que em muitas empresas os empregados não ficaram satisfeitos com o nível, duração ou qualidade do treinamento a que se submeteram. Do ponto de vista da empresa, a falta de preparo do pessoal para a utilização da tecnologia impede a obtenção plena dos resultados pretendidos.

Outro aspecto interessante é o nível hierárquico em que se deu mais claramente a percepção do impacto da inovação tecnológica. Embora em diversas empresas os impactos tenham sido percebidos em todos os níveis da organização, em algumas essa percepção ficou restrita à gerência e à diretoria. No caso do banco comercial, ainda é possível imaginar uma ligação entre o nível dos objetivos pretendidos e o locus da percepção dos impactos, mas outros fatores podem estar agindo: o grau de envolvimento e de participação dos diferentes níveis e grupos, o período de tempo transcorrido e o tipo de inovação. $O$ assunto provavelmente só ficaria esclarecido através de uma pesquisa específica.

\section{UMA COLEÇÃO DE RESULTADOS INESPERADOS}

A nossa pesquisa mostrou a ocorrência de resultados inesperados com a adoção de novas tecnologias pelas empresas. Vejamos o caso da empresa $O$ Estado de S. Paulo, que se reenxergou por causa da tecnologia. A empresa é conhecida por publicar um dos mais importantes jornais díários brasileiros, tem 6.000 empregados e fatura 400 milhões de dólares por ano. Começou a automatizar a sua redação por causa de pressões da área industrial. Seu pessoal de redação aguardava a inovação com ansiedade, já que o futuro previsto dos jornais passava obrigatoriamente por essa etapa. Os demais jornais brasileiros de grande porte já haviam dado seus passos iniciais na informatização de suas redações quando O Estado instalou um projeto piloto em 1988. Os resultados da implantação do sistema de automação da redação em 1991 foram muito bons, mas a revolução não parou por aí.

A empresa passou a utilizar cada vez mais os recursos de telecomunicações e a integrar seus recursos tecnológicos. Ficou claro, então, que a visão da empresa precisava ser redefinida e que novos negócios surgiam dessa integração. Atualmente, O Estado de S. Paulo é uma empresa que se localiza no segmento de informação, vendendo informação sob diversas formas para diferentes tipos de consumidores. Os jornais da casa (O Estado de $S$. Paulo e Jornal da Tarde) são apenas a forma mais tradicional de se realizar essa venda e a eles foram acrescentados novos canais de distribuição: o jornalfax, o telex, o rádio, o broadband e a conexão on-line. Esses novos canais têm suas características específicas em termos de tipo de informação, freqüência de publicação, nível de detalhe, tipo de público alvo etc.

Outra forma de tecnologia teve impacto significativo no Gallup. Introduzido recentemente no mercado brasileiro, o fax acelerou de forma revolucionária o ciclo do trabalho do instituto: a solicitação do serviço hoje chega com detalhes inéditos, minutos depois de decidida pela diretoria do cliente, é analisada e uma proposta de prestação de serviços pode ser encaminhada em questão de horas. A negociação dos detalhes pode ser feita com os recursos da velocidade e da imagem gráfica, de modo que um projeto mais ajustado às necessidades do cliente é definido em menos de um dia. A apresentação de resultados prévios e das conclusões finais também pode ser feita de forma instantânea, enquanto o relatório segue pelo correio. Todo esse trabalho era feito, na melhor das hipóteses, em muitos dias, talvez semanas.

Também nos escritórios de advocacia a introdução do fac-símile provocou alterações na forma de trabalhar. Agora os textos podem ser submetidos aos clientes em versões preliminares com muita agilidade e receber alterações manuscritas que são devolvidas imediatamente ao escritório. Numerosas trocas de correspondência que levavam dias para se completar, hoje podem ser feitas em meia hora. As vantagens são maiores quanto mais distantes ficam os advogados de seus clientes e quanto mais vitais são os assuntos tratados.

Outro resultado inesperado e freqüentemente observado é a mudança de patamar das pessoas encarregadas das atividades gerenciais, em termos de habilidades pessoais. $O$ processo de introdução de novas tecnologias muitas vezes exige uma profunda avaliação da empresa e uma revisão abrangente 
dos seus processos e mecanismos de controle. Nessa ocasião, surge a oportunidade de aperfeiçoamento dos gerentes e de consolidação de conceitos fundamentais para a gestão da empresa, mas, na maioria dos casos, os gerentes não tinham esse objetivo específico em mente quando decidiram pela inovação tecnológica.

\section{AS GRANDES ALTERAÇ̃̃ES DA TECNOLOGIA}

A adoção de novas tecnologias muitas vezes leva a grandes alterações nas empresas. Essas mudanças podem se referir à estrutura organizacional, à alocação de recursos ou à distribuição de tarefas entre as pessoas. Podem ocorrer, também, mudanças de comportamento nas pessoas, com o surgimento de resistências e reações negativas. Vejamos alguns exemplos.

Os escritórios de advocacia estão passando por grandes alterações por causa da adoção de inovações tecnológicas. A tecnologia básica utilizada durante décadas nesses escritórios era das mais simples: trabalho manual seguido de datilografia em máquinas de escrever convencionais e complementado por controles manuais. Mesmo a introdução de máquinas de escrever elétricas na década de 70 não chegou a alterar de forma significativa a forma pela qual o trabalho era feito. Uma primeira mudança interessante decorreu da introdução de copiadoras tipo "xerox" no mercado. De repente, o processo de criação de documentos, de distribuição de cópias e de arquivamento foi alterado. Mais recentemente, a introdução dos programas de processamento de textos e a utilização de impressoras laser foram responsáveis por alterações substanciais nesses escritórios. As novas tecnologias recentemente introduzidas vieram mudar tanto a forma de realizar o trabalho, como a velocidade de execução das tarefas, a qualidade do produto final, a capacidade de resposta do escritório e os custos globais de operação.

Nas agências de propaganda, a tecnologia de informação está provocando grandes reviravoltas. Tanto nas agências grandes como nas pequenas, $a$ informatização fez desaparecerem etapas do processo de trabalho, provocou a aglutinação de tarefas e simplificou drasticamente algumas rotinas. A Guimarães Publicidade ilustra bem o caso. A empresa tem 72 empregados e fatura quase 2,5 milhões de dólares por ano. Em termos de prestação de serviços, as agências de propaganda se dividem em duas partes: a da criação e a da veiculação. A primeira é essencialmente artística, voltada à criação das peças que compõem a campanha publicitária de cada cliente. A veiculação é a área basicamente administrativa que programa e controla a exibição das peças nos diversos veículos que constituem a mídia: jornais, revistas, rádio, televisão etc. Os impactos da tecnologia e os ganhos em cada uma das áreas são muito diferentes.

Anteriormente, a criação e a finalização eram etapas seqüenciais realizadas por pessoas diferentes na Guimarães. Com o emprego de novas tecnologias a partir de 1990, as duas atividades foram fundidas numa só, com redução de prazos, melhoria de qualidade e eliminação da função de arte-finalizador. Em outra parte das agências, a da veiculação, onde é feita a programação das inserções das peças publicitárias, as novas ferramentas vieram substituir por completo a máquina de escrever, as muitas horas de tentativas de encaixe das programações e os rascunhos rabiscados.

O quadro 3 mostra os principais exemplos de resistências à introdução de inovações mencionados pelos gerentes das empresas entrevistadas. Observase que o medo inicial é a mais freqüente das resistências à inovação e o principal foco de resistência e que a resistência foi maior nos casos em que a tecnologia utilizada era relacionada com a informática.

Por outro lado, a introdução da rede de microcomputadores em empresas como o Gallup freqüentemente desperta resistências de diversos tipos. Em especial, durante anos esses institutos utilizaram processamento de dados de forma centralizada, de modo que se desenvolveu neles um grupo de pessoas que não apenas controlava toda uma atividade crítica, mas que regulava o próprio ritmo de funcionamento da empresa. As redes de computadores, como exemplo de processamento de dados descentralizado, obrigam ao desmantelamento deste modelo centralizado, já que pressupõem que cada usuário final da informação tem acesso direto e imediato aos dados de que necessita para o seu trabalho. Os núcleos centralizados resistem à idéia de descentralização com todos os argumentos.

Essas resistências e outros focos de dificuldades devem ser enfrentados para que os resultados desejados sejam alcançados. Por outro lado, as provi- 


\section{Quadro 5}

\section{Principais conseqüências das inovações tecnológicas em empresas selecionadas}

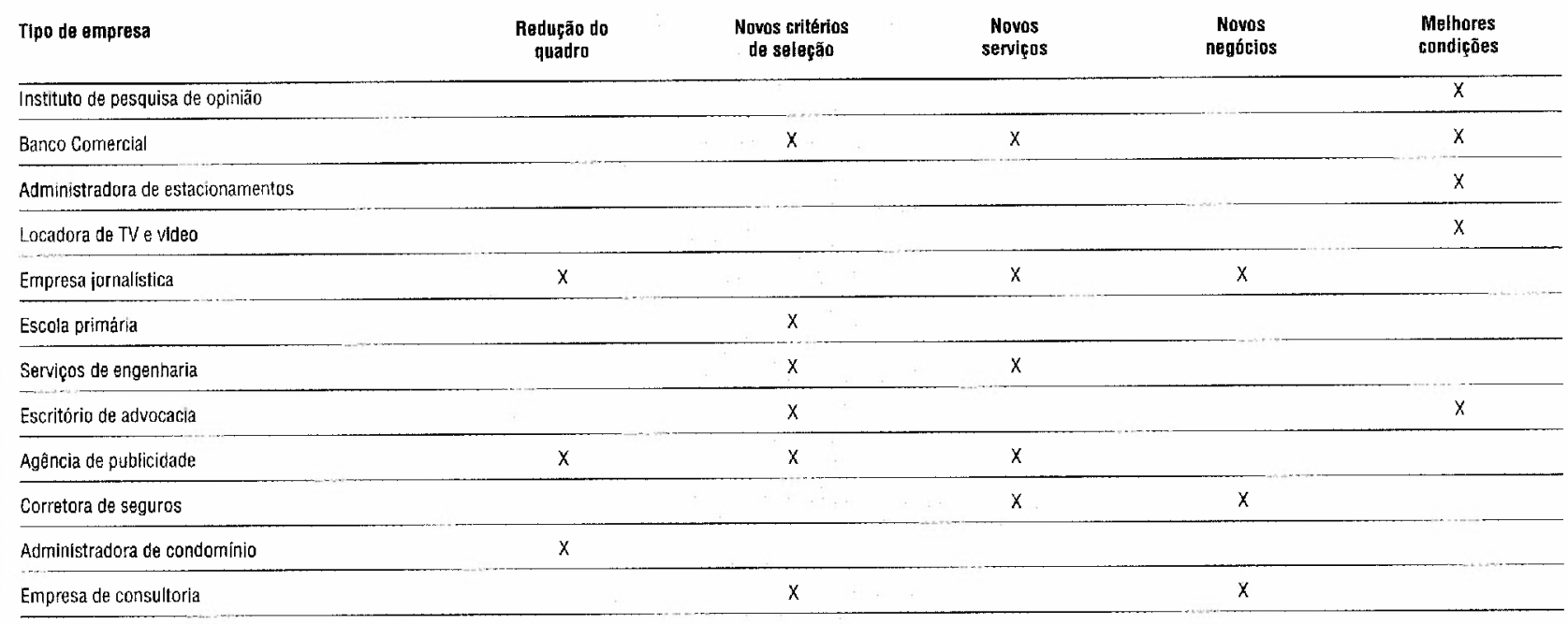

dências necessárias devem ser tomadas para garantir que sejam obtidos os melhores resultados da nova tecnologia. Embora lógica, esta proposta não é a regra entre as empresas entrevistadas. A preparação das empresas para a adoção das novas tecnologias é pobre e o pessoal se ressente disto, ficando preocupado e insatisfeito, como pode ser observado no quadro 4 . É de se supor que algumas vezes este fator pode ter sido o motivo de resultados demorados e limitados nas experiências com novas tecnologias.

Uma possível exceção foi identificada neste caso. Durante a implantação de alterações significativas nos procedimentos do banco Itaú, é organizada uma equipe itinerante, que percorre as praças onde o banco atua, para a divulgação das novidades junto aos empregados dos diferentes níveis. Além disto, foi criada uma unidade de suporte ao usuário interno, já que o número de funcionários a serem treinados era muito grande e esses funcionários estavam espalhados pelas agências. Essa unidade tinha a missão de esclarecer as dúvidas dos empregados de todos os níveis, trabalhando em qualquer agência.

\section{ALGUMAS CONSEQÜÊENCIAS INTERESSANTES}

O quadro 5 resume algumas conseqüências das inovações tecnológicas num grupo de empresas selecionadas. A partir dos dados coletados nas entrevistas, escolhemos cinco conseqüências entre aquelas mencionadas espontaneamente pelos entrevistados: redução do quadro de pessoal, novos critérios de seleção do pessoal, surgimento de novos serviços, oportunidade de novos negócios e obtenção de melhores condições de atender os clientes.

Uma das conseqüências mais interessantes é a adoção de novos critérios de seleção de pessoal, com preferência para quem já tem experiência no assunto: as empresas passaram a cobrar dos candidatos a familiaridade com as inovações tecnológicas que foram adotadas e a experiência na sua utilização. $O$ caso mais comum é o de exigir que os candidatos tenham familiaridade com as ferramentas de informática.

Outra conseqüência interessante é a oferta de novos serviços não imaginados inicialmente. Com a utilização de novas tecnologias, algumas empresas podem passar a oferecer novos serviços a seus clientes, mesmo que esse não fosse o objetivo original da inovação. No segmento das agências de publicidade, temos o caso da Guimarães Publicidade, que, com os novos recursos e com o novo perfil dos profissionais da empresa, passou a oferecer o serviço de ilustração, embora este não fosse o objetivo inicial da introdução da inovação tecnológica. 
Os impactos relativos aos quadros de pessoal estão entre as maiores preocupaçōes, cada vez que se fala de alteraçōes na tecnologia e, por conseqüência, nas características do processo de trabalho. De acordo com os dados coletados, em alguns casos houve reduçãio no número de cargos em decorrência da utilização da nova tecnologia. A redução do quadro de pessoal ocorreu geralmente por causa da eliminação da atividade, seja pela absorção por outra atividade, pela redistribuiçăo de tarefas entre os operadores ou pela execução por algum tipo de equipamento.

$\mathrm{Na}$ Guimarães Publicidade, por exemplo, $\mathrm{com}$ as novas ferramentas colocadas à disposição da criação, os cargos de arte-finalizadores foram extintos. Na empresa O Estado de S. Paulo foram praticamente eliminados todos os cargos de digitador, já que os autores dos textos passaram a fornecê-los já digitados para a composição eletrônica. $\mathrm{Na}$ empresa administradora de imóveis a redução foi drástica: o quadro diminuiu de 9 para 3 empregados, enquanto o tempo de execução das tarefas diminuiu para $50 \%$ do inicial.

Nessas e nas demais empresas foi feito um esforço de aproveitamento de pessoal, com o deslocamento de pessoas para novas tarefas. De acordo com os entrevistados, a

\begin{tabular}{|l||} 
tecnologia é muito mais que \\
apenas equipamentos, máquinas \\
e computadores. A organização \\
funciona a partir da operação de dois \\
sistemas que dependem um do outro \\
de maneira variada. Os dois sistemas \\
são simultaneamente otimizados \\
quando os requisitos da tecnologia e \\
as necessidades das pessoas são \\
atendidos conjuntamente.
\end{tabular}
quase totalidade dos empregados, cujos cargos foram extintos, acabaram sendo absorvidos em outra funções. Vale aqui a lembrança de que antes da invenção do telefone não havia telefonistas nem emprego para elas e que depois do telefone automático, o mercado promissor prometido pelos telefones manuais sumiu e, novamente, quase não há mercado para as telefonistas.

A transformação de cargos e ocupantes foi identificada como uma das conseqüências mais freqüentes da inovaçāo tecnológica. Em quase todos os casos de inovação tecnológica estudados, as habilidades pessoais (skills) das pessoas envolvidas tiveram que ser melhoradas para que fosse possivel diminuir as dificuldades iniciais e aumentar ao máximo os resultados. $O$ criador da agência de publicidade, por exemplo, não teve que aprender apenas informática e o uso de um determinado programa de computador, mas também como realizar outras tarefas, executadas antes e depois do seu job típico.

$\mathrm{Na}$ administradora de condomínios, cada empregado tinha uma funçāo bem definida: contas a pagar, cobrança, datilografia, encarregado de pessoal, contabilidade etc. Com a implantação do sistema integrado, à medida que o número de pessoas diminuía, cada empregado passou a realizar um número maior de tarefas, abrangendo um maior número de assuntos.

Outro exemplo de transformação de recursos humanos é o treinamento de professores para a utilizaçāo plena do novo método de alfabetização na escola primária. Como já mencionado, os próprios ocupantes de cargos gerenciais passam por um processo de mudança de patamar de competência com a introdução de determinadas inovações tecnológicas.

Além disto, outras consequeências foram observadas, entre as quais vale a pena mencionar o fato de que a administradora de imóveis pode aumentar o número de clientes, sem perda de qualidade de atendimento. Algumas empresas mencionaram que a nova tecnologia administrativa thes dava a flexibilidade e a agilidade necessárias para responder adequadamente às alteraçōes de normas governamentais.

\section{O CASO DA LQCASET}

A Locaset é uma empresa especializada no aluguel de aparelhos de televisão e vídeo para hotéís, eventos e clientes particulares. Tem um quadro de 20 pessoas e projeta faturar mais de dois milhōes de dólares em 1993. Seı trabalho se baseia no acompanhamento dos contratos de locação pelas diversas etapas, desde que o contato inicial é feito, passando pelo período de negociação, preparação do contrato de locação e entrega dos aparelhos, cobrança das mensalidades e retirada dos aparelhos ao final do contrato. Os contratos são muito diferentes uns dos outros, não apenas com, relação aos aparelhos locados, como também em termos de prazo, condições de pagamento e 
local de instalação. A empresa gerencia milhares de contratos de aluguel simultancamente, com uma equipe de seis pessoas.

As maiores preocupaçōes da empresa são garantir atendimento ágil e rápido a custo baixo, para que seus preços possam ser compctitivos.

Duas mudanças tecnológicas alteraram substancialmente a forma da I.ocaset operar e os resultados de sua operaçăo. A primeira ocorreu há seis anos e correspondeù à adoção do telefone como principal meio de comunicação entre a empresa e seus clientes. Nessa mesma linha, o fax passo11 a ser intensamente utilizado na transmissão da documentação de locação a partir de 1991. A segunda mudança ocorreu com a utilização da informática na automatização dos controles operacionais e das tarefas.

A tecnologia mais importante para a empresa é a informática, que tem permitido que as rotinas de produção e de controle scjam realizadas com rapidez e correção. Além disto, a utilização das ferramentas de informática tem permitido melhorar o nível de controle sobre o próprio negócio, seja pelas melhores condiçóes de planejamento, seja pela possibilidade de organizar os dados para análise.

O serviço de locação de aparelhos envolve a realização de uma seqüência de atividades que tem início na negociação com o cliente, seguida da análise de crédito, preparação e assinatura do contrato de locação, instalação dos aparclhos, cobrança das parcelas mensais e remoção dos aparelhos ao término do contrato. Esta seqüencia cra realizada de forma estrita, por equipes e pessoas diferentes. O ritmo do processo era determinado pelo deslocamento da pasta de documentos de uma estação de trabalho para outra. Essa maneira de trabalhar limitava em muito a agilidade possivel para o sistema.

A informática começou a ser utilizada em 1990, quando os contratos passaram a ser cadastrados ao final do processo básico, de modo a ser possível automatizar o faturamento e a emissão dos carnês de pagamento. Da mesma forma que jả havia ocorrido com o incremento da utilização do telefone, a nova tecnologia interferia com uma das extremidades do processo, mas o processo em si permanecia intocado. Para alterar substancialmente os parâmetros de descmpenho do processo era necessário alterar a mancira de realjzar o trabalho.

Um novo sistema informatizado, que interliga os postos de trabalho e controla as operaçōes, foi desenvolvido. A partir de então, todas as informações a respeito dos diversos contratos cstāo disponíveis simultaneamente a todas as pessoas envolvidas, o que permite que cada caso scja resolvido muito mais rapidamente. Não apenas as pessoas das diversas áreas da empresa passaram a trabalhar de forma muito mais integrada, como também uma mesma pessoa passou a scr capaz de realizar muitas atividades do processo. As atribuiçōes dos empregados foram redefinidas e o trabalho passou a ser feito pelo grupo de pessoas e não mais em seqüencia estrita de estaçōes.

Embora o sistema informatizado já tenha causado extensas alteraçōes na forma da Locaset trabalhar, percebe-se que é possível modificar ainda mais a forma de trabalhar e obter resultados ainda melhores. Esta percepção é compartilhada pela gerência da empresa, que tem hoje uma visão mais clara sobre as possibilidades da tecnologia como fator de aperfeiçoamento da empresa.

Uma rápida comparação entre as caracteristicas do processo antigo e as do novo permite verificar a diversidade de dimensões da empresa que foram influenciadas pelas alterações tecnológicas adotadas.

\begin{tabular}{ll}
\hline Processo antigo & Processo atual \\
\hline isolamento das áreas & integração das áreas \\
sequência estrita & flexibilidade \\
processo manual & processo automático \\
tecnologia simples & tecnologia atualizada \\
padrões convencionais & novos padrões de desempenho \\
\hline
\end{tabular}

A alteração dos padrões pode ser ilustrada por um fato ocorrido há alguns meses na Locaset. Na ocasião, o software utilizado na rede de dados da empresa apresentou um problema que tornava a impressão dos contratos mais lenta que o normal. Com isto, um contrato que poderia ser preparado em seis minutos estava levando quase quinze minutos para ficar pronto. As pessoas envolvidas na operação queixavam-se com razão, mas estavam avaliando o 
32. FRISCHTAK, Claudio. Banking automation and productivity change: the Brazilian experience, World Bank, p. 1, jul. 1991

33. Idem, ibidem, p. 7 desempenho do sistema pelos seus novos parâmetros. Na verdade, antes do início da utilização do novo sistema, levava-se quase duas horas, em média, para se preparar um contrato. Perto desse padrão, mesmo os insatisfatórios quinze minutos poderiam ser considerados aceitáveis.

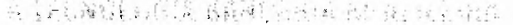

Um estudo do World Bank ${ }^{32}$ considera que a extensão da automação bancária no Brasil, particularmente o grau no qual as transações a nível de agência foram integradas nos sistemas on-line, não tom paralelo entre as economias em desenvolvimento. Mesmo para os padrōes dos países desenvolvidos, os bancos que lideram o segmento de varejo no Brasil são altamente automatizados.

Do ponto de vista da estratégia dos conglomerados financeiros brasileiros, atribuíase muita importância ao apelo da informática para atrair maior número de clientes e de contas. Dcsde a formação desses conglomerados na década de 60 , crescia a necessidade de expandir a base de clientes. Isto levou os bancos a alargarem sua linha de produtos, de modo a incluir atividades de investimento, seguros, viagens, corretagem e distribuição de valores, gestão de fundos etc. Foram obtidas substanciais economias de escala com a transformação das agências em pontos de vendas multiprodutos e a utilização da informática era imperativo evidente na automação bancária ${ }^{33}$

De modo geral, os bancos utilizam a tecnologia em duas grandes áreas: na automação bancária e no processamento centralizado do banco (parte centralizada da movimentação das contas dos clientes e das operaçôes mais a parte administrativa global do banco).

Denominamos automação bancária a aplicação de recursos de processamento automático de dados às atividades operacionais rotineiras da indústria bancária. P'or processamento, entendemos o conjunto de atividades que abrange a captura, armazenagem, organização, seleção, transmissão e apresentação dos dados utilizados na atividade em questão.

Especificamente, a automação bancária se refere às atividades de frente realizadas nas agências e postos de atendimento bancário: autenticação dos documentos, controle dos valores pagos e recebidos, calculadora, consulta e atualização de dados sobre os clientes e registro de transações. Abrange, também, as atividades administrativas da agência, como, por exemplo, o fechamento dos caixas, a emissão de resumos de movimento diário, a consulta a dados cadastrais dos clientes etc.

Além da automação bancária propriamente dita, também chamada de automação bancária interna, temos a automação bancária externa, que abrange a utilização dos caixas automáticos (ATM) e o home banking. O home banking é o nome que se dá à utilização de terminais no domicílio do cliente, para acesso direto a determinadas operações com o computador central do banco. Uma terceira categoria engloba as atividades que estão na divisa entre a atividade bancária e a comercial: a transferência eletrônica de fundos (TEF) entre as contas corrente de clientes e a conexão direta com os terminais pontos de venda (PDV) dos estabelecimentos comerciais.

Deve-se distinguir a automação bancária do suporte às atividades comerciais do banco e à gerência da agência, já que os dados, os procedimentos e o próprio tipo de trabalho são muito diferentes.

Na época da virada da década de 1980/1990, os bancos estavam optando pela mudança da tecnologia que utilizavam em automação. Essa mudança se caracterizava por três pontos: padronização dos sistemas (hardware e software), integração das agências em rede on-line e utilização de auto-serviço pelos clientes. Nos primeiros anos desta década já podemos observar as conseqüências dessa decisão: surgem agências totalmente automáticas, multiplicam-se os pontos de serviços e os quiosques tipo 24 horas e as agências completamente integradas são a regra e não a exceção. 
De acordo com os bancos, a tendência geral será de os clientes deixarem de ir ao banco, forçando-o a se colocar à disposição do cliente no seu local de trabalho ou na sua residência. Por outro lado, como já mencionado, os bancos estão preferindo que os clientes realmente só venham às suas agências para as operaçôes rentáveis.

As ATM (caixas bancárias automáticas de auto-serviço), hoje tão comuns nos grandes centros urbanos, só entraram em funcionamento quando a tecnologia em que se baseiam foi considerada suficientemente confiável e segura. Além de revolucionarem o relacionamento dos clientes com os bancos, as ATM influem diretamente na percepção que os clientes têm do banco com que operam. ${ }^{34} \mathrm{O}$ caso brasileiro do Banco 24 Horas é um exemplo de sistema interorganizacional desse tipo, em que mais de 50 bancos colocam serviços bancários básicos à disposição de seus clientes através de ATM instaladas nas maiores cidades do país.

\section{CONCLUSÕES}

De maneira geral, pudemos constatar que os empresários e responsáveis pela administração das empresas conhecem melhor os assuntos relativos à tecnologia do que supúnhamos inicialmente. Eles procuram ativamente a inovação como forma de melhorar a agilidade do atendimento aos clientes, de modernizar o processo e aproveitar melhor os seus recursos e de explorar novos segmentos de mercado.

No entanto, os resultados mencionados pelos responsáveis pelas empresas ultrapassam em muito os objetivos e as intençōes iniciais dessas mesmas pessoas.

Percebemos, também, que os impactos da introdução de inovações tecnológicas podem ser organizados em três grupos: os que interferem no trabalho e na forma de realizá-lo, os que interferem nos aspectos físicos das organizaçōes e aqueles que interferem nos aspectos psicológicos das pessoas envolvidas. Este assunto, em particular, é tão interessante que mereceria pesquisa específica.

Percebemos, também, que esses impactos ocorrem não apenas depois que a nova tecnologia passou a ser utilizada. Alguns impactos são percebidos antes mesmo de ser tomada a decisão final. É muito comum que alguns impactos psicológicos sejam percebidos ainda na fase de estudos da viabilidade da adoção de inovaçōes tecnológicas.

0 quadro 6 organiza algumas dessas idéias e apresenta exemplos dos impactos dos diversos tipos em cada etapa do processo de adoção de inovações tecnológicas.

A coletânea de exemplos aqui apresentada abrangeu diversos aspectos dos impactos das inovações tecnológicas sobre as empresas de serviços. Em particular, referiram-se às empresas instaladas no país. Acreditamos que diversos casos estão em andamento e novas tecnologias estão começando a ser utilizadas em nossas empresas, de modo que em pouco tempo teremos notícias de casos ainda mais ricos e interessantes.
34. CASH, James, KONSYNSKI Benn $R$. IS redraws competitive boundaries, Harvard Business Review, p. 134, Mar./Apr. 1985

\begin{tabular}{|c|c|c|c|}
\hline \multicolumn{4}{|c|}{$\begin{array}{l}\text { Os impactos da tecnologia ocorrem } \\
\text { antes, durante e depois da inovação tecnológica }\end{array}$} \\
\hline & ANTES & DURANTE & DEPOIS \\
\hline $\begin{array}{l}\text { Aspecios } \\
\text { referentes } \\
\text { ao lrabalho }\end{array}$ & $\begin{array}{l}\text { estratégia } \\
\text { planejamento }\end{array}$ & $\begin{array}{l}\text { ajustes na estrutura } \\
\text { organizaclonal }\end{array}$ & $\begin{array}{l}\text { management } \\
\text { qualidade do produto } \\
\text { desempenho }\end{array}$ \\
\hline $\begin{array}{l}\text { Aspectos } \\
\text { tísicos }\end{array}$ & investimento & $\begin{array}{l}\text { construç̧ăo/reforma } \\
\text { treinamento }\end{array}$ & ajustes do quadro \\
\hline $\begin{array}{l}\text { Aspectos } \\
\text { psicenlógicos }\end{array}$ & $\begin{array}{l}\text { temores } \\
\text { curiosidade }\end{array}$ & apreensăo & $\begin{array}{l}\text { frustraçâa } \\
\text { enģajamento } \\
\text { choque oultural }\end{array}$ \\
\hline
\end{tabular}

